\title{
Outer Cannula Device
}

National Cancer Institute

\section{Source}

National Cancer Institute. Outer Cannula Device. NCI Thesaurus. Code C49860.

The outer component of a double-cannula device, designed to be indwelling. 